\title{
CULTURE AND COSMOS
}

A Journal of the History of Astrology and Cultural Astronomy

Vol. 14 no 1 and 2, Spring/Summer and Autumn/Winter 2010

\section{Published by Culture and Cosmos} and the Sophia Centre Press,

in partnership with the University of Wales Trinity Saint David, in association with the Sophia Centre for the Study of Cosmology in Culture,

University of Wales Trinity Saint David, Faculty of Humanities and the Performing Arts Lampeter, Ceredigion, Wales, SA48 7ED, UK.

\section{www.cultureandcosmos.org}

Cite this paper as: Cornelia Linde (trans.) and Dorian Greenbaum (trans. and annotated), 'David Fabricius and Kepler on Fabricius's Directions, 1603-1604', Culture and Cosmos, Vol. 14 no 1 and 2, Spring/Summer and Autumn/Winter 2010, pp. 297-301.

British Library Cataloguing in Publication Data

A catalogue card for this book is available from the British Library

All rights reserved. No part of this book may be reproduced or utilized in any form or by any means, electronic or mechanical, including photocopying, recording or by any information storage and retrieval system, without permission in writing from the Publishers.

\section{ISSN 1368-6534}

Printed in Great Britain by Lightning Source

Copyright (c) 2018 Culture and Cosmos

All rights reserved 


\section{Translations of Kepler's Astrological Writings}

\section{Part III, Section 3. David Fabricius and Kepler on Fabricius's Directions, 1603-1604}

\section{Translated by Cornelia Linde and Dorian Greenbaum; annotated by Dorian Greenbaum}

We have seen Kepler's theories about directions, including examples, in Part III.1. In Part III.2, Kepler also discussed the theory of directions (see pp. 281-283). Now we present a short correspondence between Kepler and David Fabricius on the topic of Fabricius's directions, and Kepler's interpretation of them.

Taken from Opera Omnia 1, pp. 342-343; Gesammelte Werke 14, p. 406; and GW 15, pp. 22-23.

Excerpts of letters from Fabricius at Esens, 24 June 1603 O.S., and from Kepler in Prague, February 1604.

Additions to the text of $O O$ which appear in $G W$ are added between forward slashes (/).

[OO 1, p. 342; GW 14, p. 406.147-162]

FABRICIUS (letter of 24 June 1603): The current direction of the Sun to the body of Mars ${ }^{1}$ in my nativity (9 Mar 1564, 5 a.m., Ascendant $21^{\circ}$ Aquarius) strongly troubles me. I feel precluded from good fortune and the company (conversatio) of men. Please give me your honest opinion. Each man is blinded by his emotions in his own case. /And if you love me, infer its situation from your line of reasoning, and share the

\footnotetext{
${ }^{1}$ I.e., conjunction.
}

Cornelia Linde (trans.) and Dorian Greenbaum (trans. and annotated), 'David Fabricius and Kepler on Fabricius's Directions, 1603-1604', Culture and Cosmos, Vol. 14 no 1 and 2, Spring/Summer and Autumn/Winter 2010 pp. 297301.

www.CultureAndCosmos.com 
complete, written out calculation with me so that it may be a model for me, if by chance I have not understood you correctly in some things. In memory of our friendship, disclose what you sincerely feel about the whole nativity. Latitude (El. poli) 5338', longitude 30./ Does the trine of Jupiter, the Sun and Saturn have to be held as a square? /Or do you, in fact, see a trine?/ Likewise, the square of Mars is hardly equal to a sextile, yet it almost decreed (constituit) $)^{2}$ my death /when almost/ the $9^{\text {th }}$ year of my life /had elapsed on 25 December 1572/. I have felt nothing from the Sun to the square of Saturn, only an abscess in my buttocks and a hard fall, yet without [other] injury. But I await your [interpretation]. The nativity is certain and established faithfully enough through countless events and transits as well as profections $/{ }^{3}$ I have had the friendships of great men, but this was of no great use, and caused the jealousy and disparagements of poorer men, but this was not my fault, on account of the Moon in the $12^{\text {th }}$ house. I am more inclined to studies than my health will bear.

\section{Figure 1. Drawing of Fabricius' Birthchart, in Kepler's usual square chart form, using data given in the letter, cast with a modern calculation program (Solar Fire Gold) ${ }^{4}$}

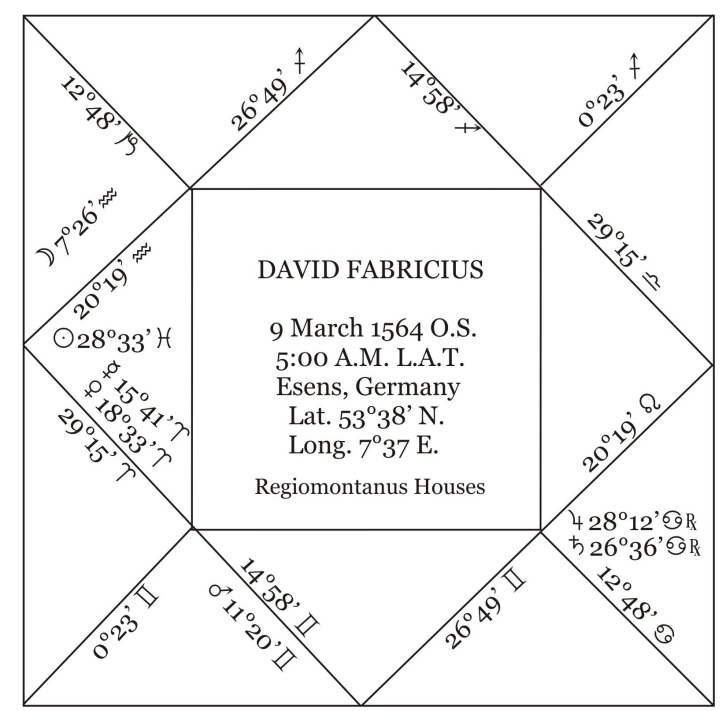

${ }^{2} O O$ has 'constituit'; $G W$ has 'consciuit'.

${ }^{3}$ Reading profectiones for perfectiones.

${ }^{4}$ No birthchart for Fabricius in Kepler's hand appears in $G W 21,2.2$. 
[OO 1, pp. 342-343; GW 15, pp. 22-23]

KEPLER (letter of February 1604): In my judgement, you ought not to worry about the direction of the Sun $[\odot]$ to the body of Mars [ $\left.\sigma^{\prime}\right]$ at this time, for it hardly reaches the $74^{\text {th }}$ year. Here is my way of doing directions:

Mars is at $12^{1 / 2^{\circ}}$ Gemini [ $\square$ ]. The Sun, on 24 May [15]64 comes to $12^{1 / 2^{\circ}}$ Gemini [ $\square$ ]. Therefore 76 days signify the same number of years. ${ }^{5}$ In 1604 , the Sun is at $8^{\circ}$ Taurus, where it was on 18 April [1564] after 40 days. ${ }^{6}$ Nevertheless, its ascending [higher in the zodiac] (because of turning towards a sextile with Saturn [Gち]) increases melancholy, zeal (studium), ${ }^{7}$ worry and diligence. By all means put your hope in the sextile of the Sun to Jupiter [G०, G4] [when it gets to] $28^{\circ}$ Taurus; within two years they will make you rich, whereas earlier in the year 1606 Saturn will pass (transierit) by square [ $ち]$ through the Sun's place. ${ }^{8}$ I do not consider the trines for the Sun and Moon $[\odot$ et $D$ ] as squares, since I do not direct them through the equator. ${ }^{9}$ It is not surprising or strange that the friendships of great men happened without benefit for you, an honest man, [since] they seek their own amusements, not your advantage. It is impossible for them to be great and lift up all the small. A wide open mouth is typical of a great man. ${ }^{10}$ You must not avoid disparagements, if you enjoy the delights of the least popular arts; no one who is famous does not endure these things. These are neither extraordinary, nor need one seek meaning in the birthchart; they appear randomly even without [being affected by] the sky.

\footnotetext{
${ }^{5}$ The Sun is at $12^{\circ} 09^{\prime}$ Gemini at midnight on 24 May 1564 . This technique is that of secondary progression, i.e. taking a day for a year.

${ }^{6}$ The Sun would have been at $8^{\circ}$ Taurus around noon on the $18^{\text {th }}$ of April 1564 .

${ }^{7}$ It is possible that Kepler meant 'study' here, in reference to Fabricius's earlier comment about being 'inclined to studies', but he uses the singular of studium, which usually means 'zeal' or 'eagerness'.

${ }^{8}$ By direction; Saturn by transit is in Capricorn in 1606.

${ }^{9}$ The Sun (Pisces) and Moon (Aquarius) in Fabricius's chart are both in signs of short ascension.

${ }^{10}$ In other words, they are (metaphorically) devouring.
} 
300 Part III. Kepler on Astrological Theory and Doctrine

Now Kepler interprets the natal chart:

The Sun in trine to Saturn $[\odot$ in $\mathrm{F} \hbar]$ and both of the superior planets conjunct adds zeal and care (studium et anxietatem). An easy intellect is from the conjunction of Mercury with Venus, but it is not too sharp; but there is some anger with the Moon in trine to Mars. I would have said that you are devoted to pleasure from the conjunction of Mercury with Venus [ 8 cum 9 ]; but I learn that in your case, the trine of Saturn and the Sun $[\mathrm{F} \hbar \odot]$ diminishes this interpretation (decretum) and makes you

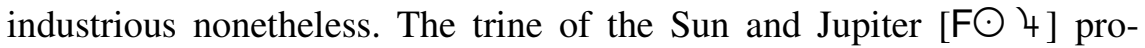
duces credulity, yet the trine of Saturn and the Sun $[\mathrm{F} \odot \hbar]$ produces [power of] judgement, and both of them joined together [lead to] a superstitious man. In these aspects, and in the position of the Moon [D], you are very similar to me. Both of us have the Moon [D] in the $12^{\text {th }}$ house in trine to Mars [Fo'], I have the Sun $[O O$ 1, p. 343] in sextile to Saturn and Jupiter $\left[\odot\right.$ in $\left.\mathrm{G}^{5}, \mathrm{G}_{4}\right]$, and a trine between Saturn and Jupiter [Fち 4 ]. Since Mercury [ $\not+]$ has been taken over by Venus [ 9 ], I therefore believe that signifies the multitude of advice and ideas and their indecisiveness (mollities). For you scatter yourself in your thinking; that is good, provided you can also discriminate. But this could be deduced instead from the trine of Mars and the Moon [Fo' $D$ ], which is common both to you and me, as it is for many.

\section{Kepler continues his discussion of directions with Fabricius:}

So that I may complete for you my manner of directing, let me continue thus: as much as the Sun has gone in 40 days ([standing] for 40 years), move the Moon forward by that much. ${ }^{11}$ For the movement of the earth alone directs the significators; but if the Moon itself were not going around it, it would always remain at the same distance from the Sun, $[G W 15$, p. 23] and would travel through the zodiac with the velocity of the Sun itself, since the yearly motion of the earth is the same as that of the Moon's orbit with the earth. For the Ascendant and the Midheaven, thus: to the right ascension of the Sun on the $40^{\text {th }}$ day ([standing] for 40 years) from the nativity add the natal hours, in this case 5 hours: in the

\footnotetext{
${ }^{11}$ This is the same as the modern technique of solar arc directions, in which all the other planets are directed at the same rate as the Sun in secondary progression.
}

Culture and Cosmos 
III.3 Fabricius and Kepler on Fabricius's Directions 301

table of houses you have the Midheaven and Ascendant to which the natal Midheaven and Ascendant have come. 